\title{
Training seed technologists
}

\author{
M. J. HILL \\ Seed Technology Centre, Massey University, \\ Palmerston North
}

ABSTRACT. The Seed Technology Centre at Massey University was established in 1976, An outline of the courses offered and personnel trained during the first 4 years of its operation is given. The success of the Centre in providing training for both technicians and post-graduate students from overseas, and the role of Masscy University in the training of researchers and servicing personnel in the New Zealand seed industry are also discussed.

Key words: Seed technologists, training, Massey University.

\section{INTRODUCTION}

Seed technology programmes can be found throughout the world in all stages of development. No two programmes are exactly alike. The development of a seed technology training programme which encompasses all aspects of technology is not easy. In the late 19th and early 20th centuries much developmental and organization work was undertaken in developing seed programmes, particularly in Europe and North America. However, it is really only in the past 20 to 25 years that many countries have put a new emphasis on seed technology and training programme development.

Often, seed technology programmes develop in different countries on their own, with little reference to similar programmes operating in other countries. Nevertheless, great advances have been made towards meeting a global need for trained seed technologists (Landenmark, 1975).

For some years American state universities such as Mississippi and Oregon have been actively involved in training seed technologists. More recently the Seed Technology Centre at Massey University and the programme at the University of Edinburgh have added new opportunities for training in this field. The ISTA and international aid organizations have also sponsored a number of short-term training programmes. These efforts show that the need for a continuing input in the training of seed technologists is becoming more widely recognized throughout the world.

\section{TRAINING}

The Seed Technology Centre at Massey University was established in 1976. It is funded by the New Zealand Ministry of Foreign Affairs under its bilateral aid programme for developing countries, In broad terms its role is to promote and improve production, processing, quality control and distribution of seed of crops which have economic and social significance in the developing world, through a programme of training and research. Within its programme the Centre offers three main levels or types of training. At the technician level the Centre offers a 4-month residential course each year over the summer (November-February inclusive). The Centre also accommodates fulltime post-graduate students studying for the Diploma of Agricultural Science (1 year), M. Agr. Sc. (2 years) and Doctor of Philosophy (4-year plus) courses. In addition, the Centre caters for students carrying out post-graduate studies in other agricultural fields (e.g., horticulture, plant health, agronomy) who wish to take one paper in seed technology as part of their course work.

Another aspect of the Centre's contribution to world seed technology is the organization of regional workshops every alternate year at an overseas venue. The purpose of these workshops, usually of approximately 3 weeks' duration, is to bring together seed technologists from the South and South-east Asian and Pacific regions in a specialized and intensive training course which concentrates on seed technology within a tropical agricultural environment. The Centre held a very successful workshop in Thailand in 1977 and a regional workshop in the Republic of the Philippines 
in 1978. It is currently planning a further regional workshop to be held in Thailand in 1980.

The Centre employs a director, two senior lecturers, three technicians, and a secretary.

During the first 4 years of its operation the Centre has carried out training of over 150 students (Table 1).

TABLE 1: NUMBER OF PERSONS TRAINED AT THE SEED TECHNOLOGY CENTRE, 1976-79

Certificate in Seed Technology

Diploma in Agricultural Science

M. Agr. SC.

$\mathrm{Ph} . \mathrm{D}$

Special post-graduate courses

Regional workshop, Philippines

Drying and storage workshop, Thailand

Single-paper post-graduates

This breakdown clearly illustrates the Centre's intention of concentrating on technician training rather than accommodating large numbers of students for post-graduate studies. Within the programme the ratio of technician to postgraduate trainees is approximately $4: 1$.

When these figures are broken down in terms of countries (Table 2) it is obvious that the demand for training in seed technology is an international need.

TABLE 2: NUMBER OF PERSONS TRAINED BY THE SEED TECHNOLOGY CENTRE BY COUNTRIES (1976-79)

\begin{tabular}{|c|c|c|}
\hline & $\begin{array}{l}\text { aining } \\
\text { N.Z.) }\end{array}$ & $\begin{array}{c}\text { Training } \\
\text { (overseas) }\end{array}$ \\
\hline Bangladesh & 2 & - \\
\hline Bhutan & - & 1 \\
\hline Burma & 1 & - \\
\hline Guyana & 1 & $\rightarrow$ \\
\hline India & 6 & - \\
\hline Indonesia & 12 & 1 \\
\hline Korea & 2 & - \\
\hline Malaysia & 11 & 2 \\
\hline Nepal & 1 & 2 \\
\hline Pakistan & 4 & 1 \\
\hline Papua New Guinea & 2 & 1 \\
\hline Philippines & 12 & 21 \\
\hline Sri Lanka & 3 & - \\
\hline Tanzania & 4 & - \\
\hline Thailand & 14 & 35 \\
\hline Tonga & - & 2 \\
\hline Western Samoa & 3 & 2 \\
\hline \multicolumn{2}{|l|}{ New Zealand (part-time only) 7} & $一$ \\
\hline Total & 85 & 68 \\
\hline
\end{tabular}

This output of trainees in the first 4 years of the Centre's operation is an indication of the demand for the courses the Centre is offering and an indication of the continuing success of its teaching and research programmes.

\section{THE NEW ZEALAND SCENE}

Historically, the strength of the New Zealand seed industry has been in the breeding, certification and testing of improved herbage and crop cultivars. Over recent years, however, there have been changes in this basic philosophy to include increasing emphasis on the importance of plant health and disease control, the development of plant variety rights and the release of new cultivars with a national or regional potential both in New Zealand and overseas. In addition, advances have been made in the introduction and assessment of foreign cultivars for use in New Zealand and for multiplication and re-export. The integration of the New Zealand seed certification scheme with the OECD scheme has also provided an opportunity to strengthen this aspect of the national and international seed industry. The seed testing service in New Zealand continues to be an internationally recognized and appreciated aspect of seed quality control. In the area of seed production greater emphasis is now being placed on specialist seed crop management of a wider variety of crops. This has been accompanied by a greater awareness bv growers of the technical problems and the timing of management decisions which influence seed yield. In this regard, farmers are also becoming increasingly aware of the effects of me-storage history on seed quality, particularly harvest timing, threshing and artificial drving.

The training offered within the seed technology programme at Massey University is designed to cover these basic areas of technology. Also, it is designed to ensure a broad training background bv including studies of the principles and practices of new crop evaluation and management, seed legislation, and auarantine, extension and marketing. In addition, the courses allow in-depth training in particular aspects of seed technology, e.g., seed production, testing, certification. drying and storage. Massey University, with its particular 
strength in seed technology, is therefore able to provide a comprehensive training in this particular field of agronomy.

The success of the Seed Technology Centre in providing training of both technicians and post-graduate students from overseas is now well established. However, the comparative impact of the Centre in training New Zealanders involved, or likely to be involved, in servicing the New Zealand seed industry is very limited.

Table 3 gives an estimate of the number of trained seed technologists in New Zealand within the research and servicing areas of the seed industry.

TABLE 3: ESTIMATE OF PERSONNEL INVOLVED IN SEED RESEARCH AND SERVICING WITHIN THE NEW ZEALAND SEED INDUSTRY (MAN-YEARS)

\begin{tabular}{lcccc}
\hline & \multicolumn{2}{c}{ Research } & \multicolumn{2}{c}{ Servicing } \\
\cline { 2 - 5 } & $\begin{array}{c}\text { Scientists and } \\
\text { Techni- } \\
\text { cians }\end{array}$ & $\begin{array}{c}\text { Seed } \\
\text { Anal- } \\
\text { ysts }\end{array}$ & $\begin{array}{l}\text { Field A dvisory } \\
\text { Officers }\end{array}$ & Officers \\
& & & & \\
\hline $\begin{array}{l}\text { Departmentof } \\
\text { Scientific and }\end{array}$ & & 0 & 0 & 0 \\
Industrial Research & 8 & 0 & & \\
Ministry of & & & 12 & 5 \\
Agriculture and & & 65 & 0 & 0 \\
Fisheries & 8 & 1 & 10 & 10 \\
Universities & 6 & 7 & 22 & 15 \\
Commerce & 10 & 73 & & \\
\multicolumn{1}{c}{ Total } & 32 & & & \\
\hline
\end{tabular}

The New Zealand seed crop is generally estimated to be worth at least $\$ 30$ million a year. This seed is ultimately disposed of almost equally to the export and domestic markets. The figures in Table 3 show quite clearly that we do not put much emphasis on the need to employ large numbers of trained and skilled personnel to produce seed of high quality for sale to the New Zealand farmer and overseas.

This situation is perhaps best summarized by Shillito (1974): ". . . perhaps its early success has been responsible for the current lack of interest in research in herbage seed production. Reliable supplies of high quality seed have always been available and have come to be taken for granted. Research was diverted into several new exciting fields such as soil fertility and management systems which gave spectacular results. Apart from some work with nitrogenous fertilizers practically no investigational work has been carried out in recent years to improve either the quality or yield of herbage seedcrops." While this situation has improved over the past 5 years, through the efforts of a relatively few diligent research workers, Shillito's statement is still relevant in reflecting the current lack of interest in the training and employment of seed technologists.

A few New Zealand administrators have appreciated the importance of seed as a basic agricultural input and have made genuine efforts to develop the field of seed technology to cope with the present situation. However, particularly in the servicing area, the current sinking-lid policy on seed industry personnel, on top of the previous dearth of such people, can only result in a serious deterioration in the availability of trained seed technologists.

One of the main constraints to the development of a strengthened seed industry, in terms of both research and servicing, is the problem of attracting suitably trained and qualified people to fill jobs within the industry. However, while a lack of trained people continues to be a problem within the servicing area in particular, there are also problems of an inadequate sense of vocation, incentive, support and motivation of seed industry personnel to achieve a cohesive industry backing.

A planned and concerted policy designed to improve the training, recruitment and retention of technologists within the research and servicing areas of the seed industry is essential to its future. This would encourage an improvement in the current situation of one research worker to everv $\$ 1$ million of seed production. In addition, it would allow the research and servicing levels in the industry to be increased to a point where New Zealand seed producers could be provided with the technical support they deserve.

\section{REFERENCES}

Landenmark. O., 1975. Expert consultation on seed industry development. FAO, S.I.D.P/75/7.

Shillito, N. L., 1974. Proc. Agron. Soc. N.Z., 4: 13-4. 